\title{
Compreensões da Educação Ambiental: possibilidades e desafios do paradigma da complexidade
}

\author{
Comprehensions over Environmental Education: possibilities and cha- \\ lenges of the paradigm of complexity
}

http://dx.doi.org/10.5007/2178-4582.2013v47n2p272

\author{
Filipi Vieira Amorim e Humberto Calloni \\ Universidade Federal do Rio Grande, Rio Grande/RS, Brasil
}

\begin{abstract}
O objetivo deste ensaio é refletirmos sobre a noção de complexidade para um pensar epistemológico da Educação Ambiental e a crise instalada em relação ao meio ambiente. No nosso entendimento, este aporte teórico se justifica diante da necessidade premente de problematizarmos os saberes governados pela hiperespecialização do conhecimento científico e seus reflexos nos processos educativos, principalmente em relação à Educação Ambiental. Este trabalho está estruturado em torno de algumas etapas significativas: i) a noção de emergência da Educação Ambiental; ii) o reconhecimento da complexidade no quefazer da Educação Ambiental; iii) a necessidade de uma superação do paradigma simplificador para um paradigma integrador dos saberes; iv) a consciência dos desafios da complexidade e suas questões metodológicas. A pesquisa, de natureza bibliográfica, reúne apontamentos de debates atinentes à teoria da complexidade visando a problematização da Educação Ambiental e sua importância para melhor compreender a crise ambiental instalada no mundo contemporâneo.
\end{abstract}

Palavras-chave: educação ambiental - epistemologia - Teoria da Complexidade.
This essay aims to reflect on the importance of the notion of complexity for an epistemological thinking about the Environmental Education and the crisis installed in relation to environment. In our view, this theoretical approach can be justified by the urgent need to problematize the hyper-specialization of scientific knowledge and its consequences for the educational process, particularly in relation to environmental education. This work is structured around some significant steps: the notion of the emergence of environmental education; the aknowledgment of complexity in the doing of environmental education; the need of overcoming a simplifying paradigm of knowledge for an integrative one; and the awareness of the challenges of complexity as well as its methodological issues. This bibliographical study gathers notes related to the debate on the theory of complexity aiming at questioning the Environmental Education and its importance to a better understanding of the environmental crisis installed in the contemporary world.

Keywords: environmental education $\square$ epistemology - Complexity Theory.

\section{Compreensões da Educação Ambiental}

[...] o problema do conhecimento constitui o nó górdio da epistemologia moderna. Neste sentido, o conhecimento deve comportar tanto a diversidade quanto a multiplicidade. Estamos longe de uma definição reduzida a uma só noção, como a informação, a percepção, a descrição ou a idéia. É necessário, assim, conceber o conhecimento em vários niveis, pois é um fenomeno multidimensional, no sentido de que, de maneira inseparável, é simultaneamente fisico, biológico, cerebral, mental, psicológico, cultural, social (PENA-VEGA, 2010, p. 53). 
A Educação Ambiental enquanto tema de pesquisas em âmbito nacional já não pode ser dita "nova", embora seja considerada recente por alguns pesquisadores da área (CARVALHO; FEITOSA, 2011). Esse tipo de abordagem data aproximadamente de três a quatro décadas quando, precedida por uma "ecologização das sociedades 1 " (GRÜN, 1996), a Educação recebeu a missão de responder alguns questionamentos referentes à crise ambiental contemporânea. Isso se deu pela convicção de que a Educação é capaz de promover transformações na sociedade, uma vez que é "uma necessidade comum a todos os seres humanos atendida segundo as crenças, os valores, os ideais e as condições materiais de cada circunstância" (GOERGEN, 2009, p. 25). Assim, frente à problemática ambiental coeva, a Natureza passa a ser assunto da sociedade civil e deixa o espaço unicamente habitado pela comunidade científica e pelos ditos amantes da Natureza, ganhando status global na busca por respostas emergenciais sobre a convivência humana na Terra (GRÜN, 1996).

Esse entrelaçamento entre Educação e questões ambientais - dita Educação Ambiental - é a problemática com que nos deparamos, pois nasceu assumindo suas características incrédulas de uma fragmentação ou simplificação possível como resultado desta união. Trata-se de duas áreas do conhecimento reconhecidamente distintas por suas singularidades, mas com abrangências próximas ao universal, dotadas de complexidade. Neste caso, universal ${ }^{2}$ no sentido objetivo, ontológico e lógico, ou seja, que diz respeito à proposição ou temática cuja essência e princípios podem ser partilhados por mais de uma área específica. Destarte, essa aproximação é dada por condições e interesses materiais da sociedade e, de acordo com Abbagnano (2007), a crise ambiental ora vivenciada convoca em uníssono inúmeras instituições sociais (econômicas, políticas e culturais) para contribuir com a sua superação.

No caso da Educação, a pesquisa sobre a problemática ambiental abarca diversas áreas do conhecimento e correntes epistemológicas variadas em seu processo de legitimação. Dentro da vasta literatura sobre as linhas epistemológicas que conduzem à produção e construção do conhecimento nos dias atuais, Libâneo (2005) apresenta, entre outras: a racional-tecnológicas; as neocognitivas; as sociocríticas; as holísticas; e as pós-modernas. Na pesquisa sobre as questões ambientais, tal e qual na Educação, diversas áreas do conhecimento mostram-se atualmente engajadas: biologia, pedagogia, antropologia, sociologia, geologia, geografia, física, filosofia, psicologia, entre outras. Essa diversidade (de áreas, epistêmica, científica) aponta o caráter dinâmico, transdisciplinar e de complexidade que deve ser levado em consideração quando falamos em Educação Ambiental (SATO, 2000).

A despeito da existência dessa diversidade, há um retalhamento disciplinar que impede o diálogo e a transdiciplinaridade entre as correntes epistemológicas e as áreas do conhecimento dispostas ao estudo da Educação Ambiental. E aqui anunciamos a justificativa do nosso ensaio, pois esses saberes separados

${ }^{1}$ Sobre a "ecologização das sociedades", ver Grün (1996, p. 15-21).

${ }^{2}$ Sobre os sentidos do termo "universal”, em caráter filosófico, ver: ABBAGNANO, Nicola (2007, p. 1169-1170). 
negligenciam a complexidade da Educação Ambiental, graças à hiperespecialização do conhecimento que predomina nas instituições de ensino e pesquisa. Por sua vez, essa hegemonia impede que os conjuntos complexos dos problemas transversais, multidimensionais, globais e planetários tornem-se visíveis (MORIN, 2011a).

Esta breve exposição reflete o objetivo geral deste ensaio: tratar da ligação entre Educação e questões ambientais a partir de duas categorias emergentes: 1) Educação Ambiental; 2) complexidade. Partindo desta premissa, é evidente que há uma conjuntura complexa intrínseca à Educação Ambiental, em que complexidade significa o contrário daquilo que é simples, e que pode ser explicado com argumentos resultantes de uma visão fragmentada, compartimentada, separada e disjunta. Defendemos a tese de que ao produto do processo entrelaçado entre Educação e questões ambientais não se pode atrelar outro predicado que não seja complexo, pois as características próprias dessa união são dotadas de complexidade. Em tempo, destacamos o fato de que nossa abordagem metodológica é uma discussão teórica à luz da epistemologia; portanto, a partir de agora discutiremos as possibilidades e os desafios da Teoria da Complexidade em seu diálogo com a Educação Ambiental.

\title{
(Re) conhecendo a complexidade da Educação Ambiental
}

\begin{abstract}
[...] há uma compreensão comum [...] da inadiável necessidade de se resgatar a comunicação, o diálogo, a relação de sentidos e significados entre os múltiplos setores do conhecimento [...], objetivando uma percepção de conjunto, de interfaces dinâmicas, de enredamento dos saberes numa totalidade significativa (CALLONI, 2006a, p. 15).
\end{abstract}

A possível efetividade da Educação Ambiental, no Brasil, está assumidamente exposta na Lei Federal 9.795, de 1999 (BRASIL, 1999). Conforme os parâmetros legais, a referida lei dispõe sobre a Educação Ambiental e sobre a Política Nacional de Educação Ambiental. Com objetivos inter, multi e transdiciplinares, e que reconhecem a necessidade da complexidade e do pluralismo acerca da temática, a lei garante seu desenvolvimento em todas as disciplinas do Ensino Fundamental, Médio, Superior e educação não-formal.

Após a homologação da lei, alguns notáveis avanços ao longo dos anos são dignos de menção, entre eles, a negação da Educação Ambiental enquanto disciplina isolada, tal como prevê o modelo educacional predominante atualmente, segundo o qual o ensino e a aprendizagem dão-se pelo processo de fragmentação e simplificação daquilo que é complexo, difícil de ser explicado em sua totalidade. Concomitantemente, a Educação Ambiental não segue uma linha epistemológica consensual entre os pesquisadores da área, e seus conceitos apresentam-se, metaforicamente, como uma babel polifônica. Ou seja, estamos diante de um impasse entre a necessidade de conceitos que funda- 
mentem e legitimem a Educação Ambiental e, ao mesmo tempo, enfrentamos o risco de a encerrarmos em um conceito fechado e fragmentado, incapaz de dialogar com as mais variadas áreas do conhecimento - necessidade inegável à Educação Ambiental, sobretudo por sua essência de complexidade.

Diante do exposto, é imprescindível reconhecer que a falta de conceitos não é de todo mau. Esse fato contribui para o crescimento das discussões em torno da temática, proporcionando adesão e engajamento por várias áreas do conhecimento, tal como sugerem os princípios da Educação Ambiental, mencionados na referida lei. Por outro lado, o encerramento conceitual oferece o risco do não reconhecimento da interligação real que há entre as partes questões sociais, ambientais, econômicas, educacionais, políticas, culturais, de processos formativos, etc. - e o todo da crise ambiental contemporânea, ou seja, a complexidade a ser reconhecidamente assumida.

Esse risco iminente (sobre o isolamento disciplinar e epistêmico) está relacionado ao modelo de apropriação e construção do conhecimento impregnado ao longo da história em nossa sociedade, desde as formulações propostas por René Descartes (ANTISERI; REALI, 1990; RUSSEL, 2001). O status quo da produção do conhecimento no Ocidente segue praticamente as mesmas premissas da revolução científica ${ }^{3}$ do século XVI e os moldes de seu posterior desenvolvimento, até o século XVIII ${ }^{4}$ e XIX, porém, com algumas tendências pedagógicas em crise e outras emergentes a partir do século XX. Essa manifestação de crise ainda não se solidificou a ponto de modificar o status quo, mas põe em xeque uma série de certezas seculares que servem de base para a pesquisa acadêmico-científica e para a legitimação do conhecimento em pleno século XXI. Esse aparato pedagógico em crise acaba por ascender a uma fase de transição (SANTOS, 2006).

Nesse ascenso das epistemologias emergentes (e talvez emergenciais) encontramos a Teoria da Complexidade, cunhada e sistematizada como pensamento complexo pelo pensador francês Edgar Morin (2011b). O próprio nome que designa tal concepção epistêmica é sugestivo à emergência do reconhecimento da complexidade do mundo, das coisas, do pensamento, da pesquisa, etc. A proposta construída por Morin é um caminho inverso ao proposto pela ciência moderna, sobretudo nos aspectos de fragmentação do conhecimento e da dicotomia das dualidades à luz do cartesianismo (DESCARTES, 1979). O que está em jogo é a afirmação da necessidade de uma (re)ligação dos saberes que se oponha ao processo de atomização, uma vez que a epistemologia moderna não comporta diversidade e multiplicidade.

O propósito do processo de atomização diz respeito à divisão, à fragmentação e à disjunção das partes em relação ao todo. Pensemos num átomo como

\footnotetext{
${ }^{3}$ Além de René Descartes, Santos (2006) refere-se a outros autores "responsáveis" pela racionalidade científica hegemônica e, ao mesmo tempo, em crise atualmente. Entre as teorias e leis que fundamentam e organizam a racionalidade dominante, o autor aponta: a teoria heliocêntrica, de Copérnico; as leis de Kepler; as leis de Galileu; as proposições de Newton; e a consciência filosófica de Bacon.

${ }^{4}$ Sobre o século XVIII, Calloni (2006b) dá notabilidade ao Iluminismo (Aufkläerung), movimento intelectual e cultural que buscou romper com as práticas religiosas predominantes e com a visão medieval de homem e de mundo. Esse movimento se deve, segundo Calloni, à crença de que só a Razão humana seria capaz de compreender o mundo.
} 
a menor partícula capaz de caracterizar um elemento químico, ou a menor das partículas que formam as substâncias. A atomização do conhecimento tratará cada problema pela ideia de átomo, e buscará nos recônditos fragmentos da realidade a explicação de um fenômeno maior que não pode ser compreendido em sua totalidade quando estudado pela simplificação. Esse princípio inaugurado pela epistemologia moderna vem à tona quando Descartes (1979, p. 37, 38), referindo-se ao alto grau de complexidade de uma situação ou fenômeno a ser analisado, estudado ou pensado, propôs, em seu $2^{\circ}$ preceito ${ }^{5}$, "dividir cada uma das dificuldades (...) em tantas parcelas quantas possíveis e quantas necessárias (...) para melhor resolvê-las". Esse preceito inaugura o reducionismo cartesiano, base para o modelo disciplinar do ensino que vigora de maneira sempiterna no âmago do tempo presente, base para o modelo de atomização do conhecimento.

Mas, por que a Educação Ambiental não pode ser pensada a partir do processo de fragmentação e atomização do conhecimento? Porque em sua origem histórica está impregnada a complexidade; sua essência é dotada de complexidade. Assim, comungamos com Edgar Morin quando diz que:

\begin{abstract}
A complexidade é um desafio ao conhecimento, não uma solução. Quando dizemos "isso é complexo", confessamos nossa incapacidade de dar uma descrição ou uma explicação simples, clara e precisa. Sentimos que aspectos diversos, ou seja, contraditórios, estão ligados, mas sem que possamos percebê-los. Para nós, tudo é incerteza e confusão, e como é cada vez mais frequente repetirmos "isso é complexo", somos cada vez menos capazes de descrever e explicar, mas sem ter consciência dessa incapacidade. Em resumo, o "isso é complexo" expressa nosso embaraço, nossa incapacidade de definir de modo simples, de denominar com clareza, de ordenar nossas ideias. O conhecimento complexo é uma tentativa de responder a esse desafio (MORIN, 2010, p. 189).
\end{abstract}

Ou seja, não há uma explicação simples sobre a Educação Ambiental, não há uma descrição concisa, breve ou clara, distinta ou esclarecedora, isso porque ela mesma é complexa, não cabe em conceitos fechados. Aliás, visto seu surgimento como indicador de uma questão global sem resposta e com a tarefa de responder à sociedade sobre como enfrentar a crise ambiental contemporânea, com o auxílio mútuo da Educação, a Educação Ambiental filia-se e encontra-se no contexto da complexidade. É claro que nem todas as pesquisas em Educação Ambiental estão pautadas nessa argumentação, do mesmo modo que nossa intenção não é propor uma padronização à pesquisa em Educação Ambiental - até porque essa tendência sobrevive enquanto paradigma dominante - mas de elucidar elementos invisíveis ao olhar disjunto, fracionado e

${ }^{5}$ Tendo por parâmetro a Lógica estudada em seu tempo, Descartes julgou que muitos dos preceitos desta ciência eram bons, porém outros tantos considerou supérfluos e nocivos. Assim, Descartes resolveu elaborar para si 4 preceitos, segundo os quais lhe bastariam desde que não deixasse uma só vez de observá-los (Cf. DESCARTES, 1979, p. 37, 38). 
simplificador. Para evitar um mal entendido, como sói acontecer ${ }^{6}$, o pensamento complexo não logra ser uma epistemologia azáfama, tampouco deve ser entendida como sinônimo de balbúrdia, pois, como bem advertiu Morin (2010, p. 189): “A complexidade é um desafio ao conhecimento, não uma solução".

Para entendermos a conjunção entre Educação Ambiental e complexidade, partimos para uma discussão sobre a questão paradigmática que envolve o conhecimento. Vamos pensar o paradigma dominante (simplificador) e o paradigma emergente (complexo): a discussão trilha rumo ao desafio do pensamento complexo.

\section{Pensando a questão paradigmática}

\begin{abstract}
[...] a crise do paradigma da ciência moderna não constitui um pântano cinzento de cepticismo ou de irracionalismo. É antes o retrato de uma família intelectual numerosa e instável, mas também criativa e fascinante, no momento de se despedir, com alguma dor, dos lugares conceituais, teóricos e epistemológicos, ancestrais e íntimos, mas não mais convincentes e securizantes, uma despedida em busca de uma vida melhor a caminho doutras paragens onde o optimismo seja mais fundado e a racionalidade mais plural e onde finalmente o conhecimento volte a ser uma aventura encantada (SANTOS, 2006, p. 58).
\end{abstract}

Um paradigma, entre as diversas análises e noções sobre o termo encontrado nas contribuições de Thomas Kuhn (1996), é todo conhecimento individual e coletivo que na comunidade científica vigora por um determinado período, em um contexto histórico particular e datado, que diz respeito a um conjunto de certezas e/ou verdades elaboradas sob as circunstâncias materiais de cada época. Chamamos de paradigma dominante a proposta da ciência moderna, ciências clássicas, que resultou na fragmentação do conhecimento tal como o conhecemos hoje: fechado e hiperespecializado em um modelo disciplinar que não se reconhece como integrante de um sistema. Ao contrário disso, chamamos de paradigma emergente, entre outros, a Teoria da Complexidade, com referência nas contribuições do pensamento complexo de Edgar Morin.

A proposta secular de uma visão dicotômica entre ciências naturais e ciências humanas parece não se autossustentar na ótica da crise do paradigma dominante. Essa distinção, hoje, faz pouco sentindo e carece de utilidade, pois o avanço recente de áreas como a física e a biologia abala os conceitos desse cientificismo primevo. Assim, "à medida que as ciências naturais se aproximam das ciências sociais estas aproximam-se das humanidades. O sujeito, que

\footnotetext{
${ }^{6}$ No livro “A cabeça bem-feita”, Morin (2011a, p. 10) esclarece: "Os que não me leram e julgam-me segundo o 'disse-me-disse' do microcosmo atribuem-me a idéia bizarra de uma poção mágica, chamada complexidade, como remédio para todos os males do espírito. Ao contrário, a complexidade, para mim, é um desafio que sempre me propus a vencer".
} 
a ciência moderna lançara na diáspora do conhecimento irracional, regressa investido da tarefa de fazer erguer sobre si uma nova ordem científica" (SANTOS, 2006, p. 69).

O indivíduo conhecedor ou observador da realidade, o sujeito do conhecimento das ciências clássicas, em busca de fundamentos fartos de certezas, foi afastado e se afastou do objeto que buscava conhecer. Fato dominantemente recorrente desde o século XVI até as primeiras décadas do século XX, haliêutico contribuiu para a soberania do paradigma dominante por mais de 400 anos sob as premissas da ciência moderna. A dicotomia entre sujeito e objeto nasceu pela característica de um conhecimento que deveria partir das idéias inatas, onde a interferência de valores humanos, místicos e religiosos não validaria o conhecimento. Ainda no século XIX, e antes da primeira metade do século XX, o método de apropriação do conhecimento partia do princípio do racionalismo e do positivismo. Antes desse período, poucas foram as vozes notáveis a uma mudança epistêmica, e quando ocorreram não encontraram interlocutores que estivessem além das margens dos movimentos que se opunham ao modelo hegemônico.

O paradigma dominante que predominava nas ciências naturais igualmente avançou o campo das ciências sociais e construiu redomas fronteiriças às ciências humanas. De uma invasão metodológica nas ciências sociais para um isolamento das ciências humanas. No século XIX, com o surgimento das ciências sociais emergentes, o paradigma dominante tornou-se modelo global de racionalidade, excluindo toda pretensão humanística como história, filosofia, literatura, teologia, etc. (SANTOS, 2006).

Com a prevalência do paradigma simplificador dominante, o método para o alcance de uma certeza ou verdade científica deveria ser sempre o mesmo: o rigor da ciência transforma o "fenômeno" em números, quantifica simplificando o objeto, e reduz a possibilidade de comunicação com outros "fenômenos" e respectivos campos do saber. Assim, cada área especializada estuda seu campo restrito e fortalece a disjunção entre a variedade de conhecimentos e saberes. Isso acaba por desencadear um totalitarismo epistemológico que nega a validação do conhecimento por outros modos de alcançá-lo. Não há, então, chances de escolha metodológica, não há democracia cognitiva.

Mas, por que não há uma alternativa de escolha metodológica? Por que não existe democracia cognitiva na ciência? Morin (2002) explica que dentro da comunidade/sociedade da ciência existe uma série de entraves nas relações entre os cientistas. Do mesmo modo que há, sem dúvidas, uma colaboração mútua de alimentação de determinado costume histórico-científico que reforça as características de um mesmo ideal de conhecimento: um laço fraterno e comunitário de proteção. É esse laço que propaga idéias e teorias em nome do suposto desenvolvimento e progresso da sociedade pelo caminho da ciência. A comunidade/sociedade científica revela em si o cuidado (ou pseudocuidado, se considerarmos a existência de interesses individuais nesse cuidado) com o alcance das "verdades" evitando a emissão de "falsos" conhecimentos, por isso existem os paradigmas dominantes e as imposições metodológicas. 
Subsistem, concomitantemente, na comunidade/sociedade científica (como em outros tipos de comunidade/sociedade) disputas hostis e amigáveis, conflitos que transitam entre colaboração e cooperação ou entre rivalidade e competição. São esses fatores que concedem à ciência o título e o reconhecimento de comunidade/sociedade, uma vez que tais características denotam em sua tarefa um continuum de noções e princípios teóricos que sobrevivem em meio às relações de interesses, coletivos ou individuais, comuns ou distintos. Como expõe Morin (2002, p. 55), a comunidade/sociedade da ciência é uma comunidade epistemológica que reforça ou enfraquece um ou outro paradigma, pois se trata de uma comunidade/sociedade multidisciplinar que pode dispor "de um arsenal transteórico ou transdisciplinar comum, isto é, de temas que motivam teorias diferentes". Embora exista essa motivação, prevalece o culto ao paradigma dominante pela ideia hegemônica de validação e reconhecimento do saber científico até o surgimento, sem tempo determinado, de condições que materializem o surgimento do novo paradigma.

No século XX alguns indícios da crise do paradigma dominante ficaram inscritos, deixando vestígios iniciais sobre a possibilidade e a necessidade de outras epistemologias. Os rigorosos fundamentos da ciência moderna ficam abalados quando seu método de fragmentação alcançou camadas de um mundo oculto aos olhos nus. O potencial de fragmentação e divisão chegou a um nível tão elevado que serviu de feitiço contra o feiticeiro, pois marca o princípio da incerteza ${ }^{7}$ sobre as bases da redução e da simplificação que garantem certezas na ótica do paradigma dominante. Morin (2011a) descreve duas revoluções científicas entre o século XIX e o século XX: a primeira gera a incerteza física e biológica que muda a concepção de mundo, com a termodinâmica de Boltzmann ${ }^{8}$, na descoberta dos quanta; e a desintegração do Universo proposto por Laplace ${ }^{9}$; esta burilou no surgimento das ciências da Terra, da Ecologia e da Cosmologia, dando origem a um novo espírito científico.

Nas duas revoluções científicas apontadas por Morin é possível visualizar brechas ao surgimento do novo paradigma, e é daí sua emergência. Essas conjunturas servem de marco ao reconhecimento da desordem coexistente e, às vezes, sobreposta à ordem das Leis da Natureza, até então desconsideradas pelo cientificismo de comprovação imposto pela modernidade. A ciência moderna está sob um terreno lábil. A ordem era, até então, palavra-mestre, reinava "do Átomo à Via Láctea" (MORIN, 2008, p. 51).

É a partir do princípio da incerteza e do surgimento do novo espírito científico que assentamos a hipótese de que a Educação Ambiental é complexa e pode ser compreendida pela Teoria da Complexidade. Dos apontamentos

\footnotetext{
${ }^{7} \mathrm{O}$ princípio da incerteza tem origem nas proposições de Werner Heisenberg, o qual recebeu prêmio Nobel de Física em 1932 (Cf HEISENBERG, 1962). "Esse autor demonstrou que o comportamento das partículas é totalmente imprevisível. Ao deparar-se com a impossibilidade em elaborar uma descrição objetiva da natureza sem se referir ao processo de observação, identificou tal fenômeno como uma indeterminação; o que ficou mais conhecido como princípio da incerteza" (SANTOS, 2008, p. 78).

${ }^{8}$ Ludwig Eduard Boltzmann (1844-1906), físico austríaco conhecido por suas contribuições na termodinâmica estatística ( $C f$. DAHMEN, 2006).

${ }^{9}$ Pierre Simon Laplace (1749-1827), matemático, astrônomo e físico francês.
} 
sobre as questões paradigmáticas evidenciaremos o desafio do pensamento complexo: tornar simbiontes os conhecimentos e promover a democracia cognitiva.

\title{
O desafio da complexidade
}

\begin{abstract}
Tomemos o homem como exemplo. O homem é um ser $[\ldots]$ biológico. É ao mesmo tempo um ser [...] cultural, metabiológico e que vive num universo de linguagem, de ideias e de consciência. Ora, estas duas realidades, a realidade biológica e a realidade cultural, o paradigma de simplificação nos obriga a disjuntá-las ou a reduzir o mais complexo ao menos complexo. Vamos, pois, estudar o homem biológico no departamento de biologia, como um ser anatômico, fisiológico, etc. e vamos estudar o homem cultural nos departamentos das ciências humanas e sociais. Vamos estudar o cérebro como órgão biológico e vamos estudar a mente [...] como função ou realidade psicológica. Esquecemos que um não existe sem a outra, ainda mais que um é a outra ao mesmo tempo (MORIN, 2011b, p. 59).
\end{abstract}

Apresentamos até aqui algumas noções sobre o movimento histórico de afirmação do paradigma simplificador (baseado nos princípios da disjunção, da redução e da abstração, ainda dominante) e do paradigma emergente (o paradigma da complexidade). Igualmente, apontamos as brechas resultantes da hiperespecialização do cientificismo. Como na epígrafe, o paradigma simplificador não mais se afirma. No caso do homem ${ }^{10}$, não é possível manter separados os fenômenos biológicos e os fenômenos culturais, pois uns não ocorrem sem os outros; do mesmo modo, outras características dualistas e dicotômicas da ciência moderna não mais se sustentam, como a distinção entre observador e observado, subjetivo e objetivo, razão e emoção. Partindo do exemplo do homem podemos utilizar o conceito de sistema, o da auto-organização ou simplesmente a ideia de que ordem e desordem coexistem para mostrar que o paradigma simplificador vive um estado patológico (MORIN, 2011b).

$\mathrm{O}$ movimento epistemológico da Teoria da Complexidade tem por princípio comum a tendência anti-reducionista. $\mathrm{O}$ reducionismo ubíquo nas ciências clássicas levou a comunidade/sociedade científica, até meados do século $\mathrm{XX}$, a uma série de conquistas e avanços ${ }^{11}$. Portanto, o paradigma simplificador tem seus méritos reconhecidos. Mas, sabemos que é necessário que esse modelo seja complementado. Aliás, a reconhecida necessidade de uma epígrafe.

${ }^{10}$ A palavra "homem" representa o ser humano, sem distinção de gênero, utilizamos "homem" em referência à

${ }^{11}$ Ortega y Gasset (1989) diz que o homem renasce a partir das descobertas e proposições de Descartes e Galileu. Partindo dessa referência, Lima (2006, p. 156) acrescenta: "Da crença numa terra plana, transitamos, graças aos modernos, para uma terra redonda, da terra imóvel localizada no centro de um universo finito, segundo Aristóteles, para uma terra que se movimenta como um peão, num cosmo infinito, do qual a terra é um simples satélite que gira em torno de uma estrela periférica localizada num pequeno sistema solar, presente no final da cauda da Via Láctea, numa modesta galáxia". 
complementação foi estabelecida a priori pelo próprio desenvolvimento inaudito das ciências clássicas. A ideia de complementaridade vai ao encontro do pensamento complexo a posteriori, pois o desafio da complexidade não busca anular o paradigma simplificador, mas integrá-lo.

Embora a noção de complexidade seja vista por seus opositores como um verso de pé quebrado, essa tendência sugere, desde sua etimologia latina - complexus, "o que é tecido em conjunto" (MORIN, 2010, p. 190) -, seu princípio guia: religar o que está separado para conhecer o todo, distinguir as partes sem separá-las e reconhecê-las novamente em suas inter-relações com o todo complexo. É por isso que a complexidade comporta o que separa e o que simplifica, mas rejeita uma simplificação dissociada em fragmentos incomunicáveis entre uma verdade e outra. Rejeita um conhecimento unicamente atomizado. Assim, graças ao desenvolvimento científico e tecnológico, buscamos cada vez mais compreender a realidade onde estamos inseridos. Por isso mesmo o pensamento complexo abarca as incertezas e as antinomias multidimensionais por uma necessidade do conhecimento, não por uma sucessão paradigmática historicamente natural (TARRIDE, 1995).

Salientamos, para dar cabo a qualquer mal-entendido epistemológico, o que a complexidade não é:

[...] uma espécie de catálogo no qual se acumulariam, por justa-
posição, todos os conhecimentos: físico, biológico, psicológico,
psicanalítico etc. Ao contrário, ela deve ser considerada como
um princípio de complexificação do nosso próprio conhecimen-
to, que introduz, em todas essas consciências, a consciência das
condições bio-antropológicas, socioculturais ou nosológicas do
conhecimento. Em outras palavras: o conhecimento que traduz
a complexidade dos fenômenos deve reconhecer a existência
dos seres e interrogar-se sobre o mistério do real (PENA-VE-
GA, 2010, p. 40).

Sem necessidade de circunlocução, atribuímos ao pensamento complexo dois grandes desafios: $1^{\circ}$ ) tornar simbiontes os conhecimentos das ciências naturais, sociais e humanas; $2^{\circ}$ ) a partir do anterior, tornar-se utensílio de inteligibilidade como democracia cognitiva. Esses dois desafios já estão subentendidos na emergência do pensamento complexo de Edgar Morin, mas nossa advertência remete à construção epistemológica da Educação Ambiental, embora, hipoteticamente falando, acreditemos que o potencial transformador de uma Educação Ambiental pautada nos princípios do pensamento complexo é dotado de possíveis mudanças no destino incerto da humanidade.

A ideia de uma simbiose do conhecimento direciona essa abordagem à ciência ecológica, pois o sentido do termo vem da ecologia. $O$ termo simbiose corresponde a uma série de processos e trocas vantajosas na relação entre organismos vivos de espécies diferentes (PINTO-COELHO, 2000). A simbiose do conhecimento é uma metáfora, mas mostra a possibilidade da extensão do conceito ecológico na religação dos saberes separados pelas ciências clássi- 
cas. No caso dos organismos vivos, a simbiose não oferece perdas ou danos aos envolvidos, e o mesmo pode ocorrer com o conhecimento.

A separação existente entre ciências naturais, ciências sociais e ciências humanas não resiste à magnitude do paradigma emergente. $\mathrm{O}$ ser humano - Homo sapiens - espécie tardia no Planeta Terra, é ao mesmo tempo ser biológico, ser social e ser individual. O biológico remete às características da espécie específica, que nos difere dos outros animais por nossas particularidades físicas, mentais, genéticas, etc.; ao mesmo tempo, somos seres sociais, pois mantemos relações com outros indivíduos e estamos inseridos em um contexto cultural; ainda, somos seres individuais, cada um com suas concepções de mundo e singularidades; portanto, somos seres trinos (MORIN, 1991). Nessa trilogia do humano, não há como disjuntar as partes; portanto, o Homo sapiens é também demens: há racionalidade e objetividade, mas coexiste subjetividade; há sentimentos emocionais e Razão. O que não existe é fronteira entre sapiens (o humano racional) e demens (o humano subjetivo).

Desse mesmo contexto deriva a separação das ciências naturais e das ciências humanas. A cultura humanística das artes, da poesia, da literatura e da filosofia foi distinguida da cultura científica pelo paradigma simplificador. A cultura humanística, "baseada na reflexão, não pode mais se alimentar nas fontes do saber objetivo", e a cultura científica, "baseada na especialização do saber, não pode se refletir nem pensar a si própria" (MORIN, 2011b, p. 76).

Embora Descartes tenha julgado que as humanidades não ofereciam certezas (e essa afirmação foi incorporada ao paradigma simplificador), julgando-as desnecessárias, não há como afirmar que tal o seja, ou que existam fronteiras restritas à troca de saberes entre uma ou outra. A simbiose do conhecimento seria o eixo auxiliar da complexidade na tarefa de promover a conjunção sobre a disjunção.

No mesmo rumo, a democracia cognitiva denota a complexidade quando busca resgatar o que a modernidade extraviou. Da conjunção entre ciências humanas, ciências sociais e ciências naturais, nascerá a consciência planetária e os fundamentos de uma epistemologia complexa para a efetivação da Educação Ambiental. A Educação baseada no modelo disciplinar trouxe uma série de avanços tecnocientíficos, "mas engendra um conhecimento especializado que é incapaz de compreender os problemas multidimensionais e determina uma incapacidade intelectual de reconhecer os problemas fundamentais e globais" (MORIN, 2011c, p. 78).

Acreditamos no devir de assumirmos a incerteza por salutar e depois enfrentá-la transdisciplinarmente entre ciências naturais, ciências sociais e ciências humanas. Uma mudança paradigmática traz consigo uma nova concepção de mundo. É fundamental que pensemos qual visão queremos, pois a transição paradigmática já está acontecendo. As sucessões paradigmáticas são marcadas por "modelos" metodológicos. A comunidade acadêmico-científica preconiza as questões de método para o alcance do conhecimento, para validação dos saberes. Pensando nisso, apresentaremos algumas reflexões sobre as questões metodológicas a partir da Teoria da Complexidade. 


\title{
Questões metodológicas
}

\begin{abstract}
Eu não trago o método, eu parto em busca do método. Eu não parto com o método, eu parto com a recusa, totalmente consciente, da simplificação. A simplificação é a disjunção em entidades separadas e fechadas, a redução a um elemento simples, a expulsão do que não entra em um esquema linear. [...] Eu parto também com a necessidade de um princípio de conhecimento que não apenas respeite, mas reconheça o não-idealizável, o não-racionalizável, o que foge às regras (MORIN, 2008, pp. $35,36)$
\end{abstract}

De início, e por tratarmos de questões metodológicas, lembramos Antonio Machado; façamos saber: Caminante no hay camino, se hace camino al andar (apud MORIN, 2008, p. 36). Não há um caminho. Não se pode saber de antemão onde a pesquisa nos levará. $\mathrm{O}$ trabalho de pesquisa é incerto. $\mathrm{O}$ caminho se faz caminhando. $\mathrm{O}$ aprender acontece aprendendo. Os métodos e a metodologia são visitados e revisitados a todo o momento.

Visualizamos na ideia de metodologia a dominância do paradigma simplificador, pois delimitar o caminho é o mesmo que reduzir a amplitude do conhecimento, do saber, da pesquisa, é simplificar o complexo, fragmentar e desconectar as partes do todo. Esse é um impasse que mantém o paradigma da complexidade no limbo, que reafirma a questão do método universal vicioso da ordem como elemento intrínseco ao alcance do conhecimento.

À medida que a segurança metodológica avança e propaga-se, a fragmentação e o reducionismo em nome da ordem e da linearidade científica são reforçadas. Alimentamos duas hipóteses a partir disso: 1) as delimitações impostas pela ciência moderna e absorvidas pela academia são tão prejudiciais quanto benéficas; 2) as questões metodológicas remetem aos recursos técnicos disciplinares de verificação com o objetivo de tornar eficaz a investigação.

Portanto, a metodologia da Teoria da Complexidade está restrita às ideias claras e distintas, unicamente. Não tem neutralidade. Não busca encontrar somente ordem, mas desordem igualmente. Não é um caminho só de ida, mas de ida e volta, de espiral, de conhecimento cíclico onde "a idéia de conhecer assemelha-se a de enredar" (MACHADO, 1999, p. 138). Ora, o que buscamos está ligado ao pensamento complexo e, como diz Pena-Vega (2010, p. 41), não há uma chave "para penetrar no universo da complexidade; o que existe são vias, caminhos, avenidas diferentes que conduzem em direção aos desafios dos conhecimentos". Por isso, a proposta metodológica da Teoria da Complexidade é entendida como um caminho metodológico.

A ideia de caminho metodológico justifica-se pelo aumento das próprias situações contemporâneas de evidente complexidade: a crescente deterioração dos ecossistemas; a diversidade dos problemas de saúde; o crescimento desordenado das cidades; a incerteza do destino coletivo da humanidade; etc. Vivemos um período de instabilidade, entre outros, social (econômica, políti- 
ca e cultural), epistemológica, ambiental, científica, intelectual, filosófica, espiritual, representada pela crise do discurso firmado na modernidade. Os fundamentos que por séculos sustentaram a Razão humana (com R maiúsculo), no sentido Iluminista do século XVIII, como giro potencial da emancipação humana, detentora da verdade, da ciência, da autonomia do sujeito moderno, do conhecimento, da política, da liberdade, e da cultura, como universalmente capaz de dizer de si e do mundo, encontra-se num prado hesitado. A razão (com r minúsculo) ronda a Razão:

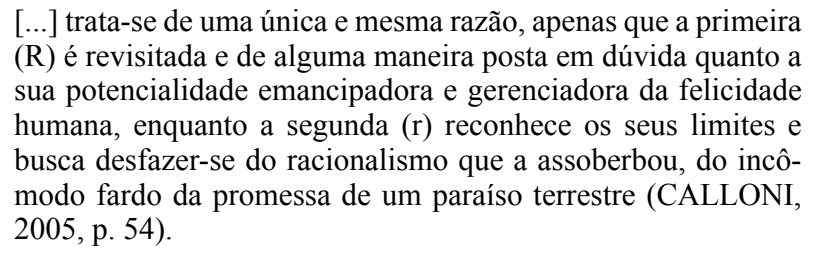

Cada ideal de Razão/razão está historicamente subscrito no moderno e no pós-moderno, respectivamente. A Razão moderna atribuiu sentido autômato à humanidade e é o que a razão pós-moderna revisita sem cautela. Assim, os fundamentos da Razão moderna sofrem o mesmo que um abalo sísmico, pois a razão pós-moderna questiona o cientificismo clássico e suas noções de verdade, objetividade, progresso, previsibilidade e ordem. A pós-modernidade está assentada, sobretudo, a um novo tipo de produção cultural holística em contraponto ao modelo epistemológico dicotômico e dualista, pois "não segue um estilo unidimensional, facilmente identificável, o seu estilo é uma configuração de estilos construída segundo o critério e a imaginação pessoal do cientista" (SANTOS, 2006, p. 78, 79).

Diante da analogia entre a epistemologia pós-moderna e sua tendência holística, afirmamos que a Educação Ambiental (enquanto objeto de pesquisa) é autóctone a essa metodologia. Diferente seria se a Educação Ambiental não partisse de uma compreensão holística, já que é processo conectivo entre as questões ambientais e a Educação. Ainda, seria uma vez mais alóctone se nossa proposta não estivesse ligada à Teoria da Complexidade.

Nosso ensaio pretende auxiliar na construção de uma discussão teórica que contribua para a Educação Ambiental na edificação do paradigma da complexidade pelo caminho da filosofia. O caminho metodológico que aqui apresentamos é um tripé sustentado pela complexidade (paradigma emergente inserido filosoficamente no contexto holístico), pela corrente epistemológica holística (fio condutor do modo de ver e pensar o mundo em sua complexidade) e pela discussão filosófica (o fermento da lucidez para o percurso espiral teórico-metodológico).

A importante contribuição da filosofia está expressamente descrita no trecho que segue, e serve de justificativa para a escolha de caminhar ao lado dela sem, contudo, desfazermos de outros saberes: 
A filosofia, ao contribuir para a consciência da condição humana e o aprendizado da vida, reencontraria, assim, sua grande e profunda missão. Como já acusam as salas e os bares de filosofia, a filosofia diz respeito à existência de cada um e à vida quotidiana. A filosofia não é uma disciplina, mas uma força de interrogação e de reflexão dirigida não apenas aos conhecimentos e à condição humana, mas também aos grandes problemas da vida. Nesse sentido, o filósofo deveria estimular, em tudo, a aptidão crítica e autocrítica, insubstituíveis fermentos da lucidez, e exortar à compreensão humana, tarefa fundamental da cultura (MORIN, 2011a, p. 54).

A partir da Teoria da Complexidade, três tarefas não podem ser deixadas fora do caminho metodológico: 1) não desvalorizar a tradição clássica das ciências naturais - revisitar o paradigma simplificador pode gerar a descoberta de questionamentos ocultos sem respostas e contribuições salutares à complexidade, mas negligenciadas pelo cientificismo; 2) não desconsiderar as dúvidas, a desordem e as incertezas - sob o risco de tornar esta proposta um fragmento, herança do paradigma simplificador; 3) evitar a paralisação da complexidade - isso ocorre quando a pesquisa não oferece contribuições significativas à construção da epistemologia emergente, de modo que ocorre uma paralisação e não há uma religação de saberes. Por fim, acrescentamos e declaramos ao caminho metodológico a possibilidade da metamorfose contínua.

\section{Considerações finais}

Para a efetivação da Educação Ambiental é necessária uma reorganização epistemológica que não seja unívoca, mas capaz de articular em conjunção as interações sociais (econômicas, políticas e culturais), ambientais, cognitivas, psíquicas, físicas, mentais, cerebrais, a partir da inter-relação não dicotômica entre os sujeitos e o mundo. Do mesmo modo, é preciso assumir a transdiciplinaridade como princípio de uma democracia cognitiva e da simbiose dos saberes. Assim, seremos capazes de construir fundamentos para a Educação Ambiental e caminhos de compreensão sobre o destino incerto da humanidade.

Pensar a Educação Ambiental a partir da Teoria da Complexidade é reconhecer o princípio conectivo entre o ser humano e a Natureza, admitindo sua característica Homo sapiens demens. Assimilar essas duas condições humanas sinaliza a necessidade de uma simbiose dos conhecimentos e a emergência de uma democracia cognitiva. Há mais no complexo mundo complexo do que somos capazes de enxergar com nosso raio visual, científico-moderno, objetificador de tudo.

O ensaio que apresentamos tem pretensões de ir além deste esboço lacônico, pois diante de uma temática tão ampla é difícil apresentar, em tão curto espaço, todos os argumentos e contribuições que possibilitariam um enriquecimento do trabalho. Do mesmo modo, o ensaio é o sinal de uma busca pelo 
conhecimento, pela construção dos saberes e pela efetivação do pensamento complexo como paradigma emergente. Ao encontro disso, há uma incessante busca pelo enriquecimento da discussão epistemológica no campo da Educação Ambiental, para que esta seja reconhecida como indispensável no contemporâneo mundo de crises e incompreensões generalizadas.

Os limites do conhecimento ligados ao cientificismo moderno deixaram no ar uma única certeza: a da indestrutibilidade das incertezas. A nau carregada com os ideais, princípios e certezas seculares não naufragou, mas em sua proa são visíveis as marcas da instabilidade, da desordem, do acaso, da necessidade da conjunção entre seus fragmentos e do reconhecimento definitivo de que fazem parte de um todo. Está prestes a acontecer o que desde sempre temeram seus tripulantes: o naufrágio.

\section{Referências}

ABBAGNANO, Nicola. Dicionário de filosofia. São Paulo: Martins Fontes, 2007.

ANTISERI, Dario; REALE, Giovanni. História da filosofia: do Humanismo a Kant. São Paulo: Paulus, 1990.

BRASIL. Lei $n^{\circ}$ 9.795, de 27 de abril de 1999. Dispõe sobre a educação ambiental. Disponível em: <http://www.planalto.gov.br/ccivil_03/Leis/L9795.htm> Acesso em: 13 out. 2011.

CALLONI, Humberto. Os sentidos da interdisciplinaridade. Pelotas: Seiva, 2006a.

Ambientes desencantados: o século XVIII e o reino das racionalidades. Ambiente \&

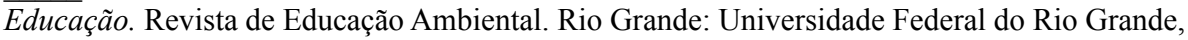
v. 11, p. 11-24, 2006b.

.A educação e seus impasses: um olhar a partir da noção de pós-modernidade. In: LAM-

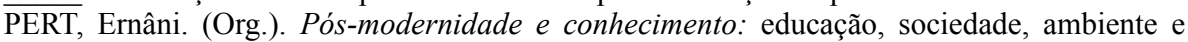
comportamento humano. Porto Alegre: Sulina, 2005.

CARVALHO, Denis Barros de; FEITOSA, Conceição de Maria Martins. A produção brasileira de teses sobre educação ambiental na biblioteca digital brasileira de teses e dissertações (BDTD): uma análise temática. Ambiente \& Educação. Revista de Educação Ambiental. Rio Grande: Universidade Federal do Rio Grande, v. 16, n.1, p. 45-58, 2011.

DAHMEN, Silvio Renato. A obra de Boltzmann em Física. Rev. Bras. Ensino Física, São Paulo, v..28, n.3, p. 281-295, 2006, . Disponível em: <http://dx.doi.org/10.1590/S1806$11172006000300005>$ Acesso em: 15 out. 2012.

DESCARTES, René. Discurso do Método. In: Coleção Os Pensadores: Descartes. São Paulo: Abril Cultural, 1979.

GOERGEN, Pedro. Formação ontem e hoje. In: CENCI, Angelo Vitório; DALBOSCO, Claudio Almir; MÜHL, Eldon Henrique. Sobre filosofia e educação: racionalidade, diversidade e formação pedagógica. Passo Fundo: Editora Universidade de Passo Fundo, 2009. 
GRÜN, Mauro. Ética e educação ambiental: a conexão necessária. Campinas: Papirus, 1996.

HEISENBERG, Werner. Physics and philosophy: the revolution in modern science. New York: Harper Torcbooks, 1962.

KUHN, Thomas. A estrutura das revoluções cientificas. São Paulo: Perspectiva, 1996.

LIBÂNEO, José Carlos. As teorias pedagógicas modernas revisitadas pelo debate contemporâneo na educação. In: LIBÂNEO, José Carlos; SANTOS, Akiko (Orgs.). Educação na era do conhecimento em rede e transdiciplinaridade. Campinas: Alínea, 2005.

LIMA, Gilson. Sociologia na complexidade. Sociologias, Porto Alegre, Ano 8, n.15, p. 136181, jan./jun. 2006, . Disponível em: $<\underline{\text { http://dx.doi.org/10.1590/S1517-45222006000100006> }}$ Acesso em: 15 de out. 2012.

MACHADO, Nilson José. Epistemologia e didática: as concepções de conhecimento e inteligência e a prática docente. São Paulo: Cortez, 1999.

MORIN, Edgar. A cabeça bem-feita: repensar a reforma, reformar o pensamento. Rio de Janeiro: Bertrand Brasil, 2011a.

Introdução ao pensamento complexo. Porto Alegre: Sulina, 2011b.

. Rumo ao abismo? Ensaio sobre o destino da humanidade. Rio de Janeiro: Bertrand

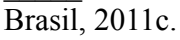
2010 .

. Meu caminho: entrevistas com Djénane Kareh Tager. Rio de Janeiro: Bertrand Brasil,

. O método I: a natureza da natureza. Porto Alegre: Sulina, 2008.

. Ciência com consciência. Rio de Janeiro: Bertrand Brasil, 2002.

LTDA, 1991.

ORTEGA Y GASSET, José. Em torno a Galileu. Petrópolis: Vozes, 1989.

PENA-VEGA, Alfredo. O despertar ecológico: Edgar Morin e a ecologia complexa. Rio de Janeiro: Garamond, 2010.

PINTO-COELHO, Ricardo Motta. Fundamentos em ecologia. Porto Alegre: Artmed Editora, 2000 .

RUSSEL, Bertrand. História do pensamento ocidental: a aventura dos pré-socráticos a Wittgenstein. Rio de Janeiro: Ediouro, 2001.

SANTOS, Akiko. Complexidade e transdisciplinaridade em educação: cinco princípios para resgatar o elo perdido. Rev. Bras. Educ., Rio de Janeiro, v.13, n.37, p 71-83, jan./abr. 2008, .

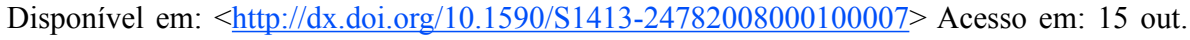
2012. 
SANTOS, Boaventura de Sousa. Um discurso sobre as ciências. São Paulo: Cortez, 2006.

SATO, Michèle. Dialogando saberes na educação ambiental. In: Encontro Paraibano de Educação Ambiental - Novos Tempos, 08-10 de novembro de 2000. Anais: seção "palestras". João Pessoa: REA/PB \& UFPB, 2000.

TARRIDE, Mario. Complejidad y sistemas complejos. Hist. cienc. Saúde - Manguinhos vol. 2, n.1, pp. 46-66, jun. 1995. Disponível em: <http://dx.doi.org/10.1590/S010459701995000200004> Acesso em: 15 out. 2012.

Submissão em: 31/01/2014

Revisão em: 10/03/2014

Aceite em:18/03/2014

Filipi Vieira Amorim é Licenciado em Ciências Biológicas pela Universidade do Planalto Catarinense e Mestre em Educação pela mesma universidade; Doutorando em Educação Ambiental pela Universidade Federal do Rio Grande (PPGEA-FURG); Bolsista da CAPES. Endereço para correspondência: Rua Major José Serafim, nº 69, Centro. Painel/SC, Brasil. CEP: 88543-000. E-mail: filipi_amorim@yahoo.com.br

Humberto Calloni é Filósofo e Pedagogo pela Universidade Federal do Rio Grande do Sul, Mestre e Doutor em Educação pela mesma universidade; Professor e pesquisador do Programa de Pós-Graduação em Educação Ambiental da Universidade Federal do Rio Grande (PPGEA-FURG). E-mail: hcalloni@mikrus.com.br 